\title{
Pricing and revenue management in a world of offer optimisation
}

\author{
Dieter Westermann ${ }^{1}$
}

Received: 19 March 2021 / Accepted: 30 March 2021 / Published online: 22 June 2021

(c) The Author(s), under exclusive licence to Springer Nature Limited 2021

On the commercial side airlines are currently going through a fundamental transformation by converting into retailers with an increasing diversity of products: airlines are adding many more features to their offers. In addition, airlines increasingly personalise the offer content by considering factors observed along the shopping process. For example, a person browsing multiple destinations during the same session is most likely a leisure customer. This development is primarily enabled by the IATA-facilitated New Distribution Capability (NDC), an industry-wide communication standard, which is gaining momentum and is being implemented by a growing number of airlines. NDC allows airlines to distribute these more tailor-made and personalised offers not only through their own website, but also via indirect distribution channels including Global Distribution Systems (GDSs) and Online Travel Agents (OTAs). For many carriers the extension of retailing capabilities to the indirect distribution channel is the prerequisite to reach enough customers to justify the significant investments into new technology and methods.

When selling through their own website or the indirect channels using NDC, an interactive shopping process between the airline and the customer is established during which the requests and replies are managed in real-time. As part of this bilateral communication many aspects, as well as personal data that the customer is willing to share can be exchanged. This interactive shopping process theoretically allows an unlimited number of tailor-made offers that are priced in line with customer expectation.

Real-time retailing will require airlines to rethink the way they construct their offers. Shifting the shopping process from searching for the lowest fare to finding the best value for money, will challenge airlines to develop sophisticated methods. Those methods must be capable of real-time

Dieter Westermann

adwestermann@bluewin.ch

1 D W R M Consulting, Abu Dhabi, United Arab Emirates identification of customer preferences at every touch point, to ultimately present offers that result in a purchase decision.

Enhancing traditional demand forecasting, pricing, and revenue optimisation to "offer optimisation" that produces enriched and personalised offers based on behavioural analytics and machine learning will lift revenue management to the next level. Offer optimisation requires fundamentally different approaches to traditional revenue optimisation: besides the additional data elements available to be included as input to offer optimisation methods, the output is also no longer limited to just determining seat prices or booking class availability. Deciding which components are to be included as part of an offer, as well as how the offer should be presented adds new dimensions to the optimisation problem. The need for new models and ways to best present the information to the customer will trigger innovative ideas. At the same time, it needs to be kept in mind that the industry is going through a transition period that will last for many years. Therefore it will be of utmost importance to address how current methods for flight/network optimisation and airline seat pricing can be best integrated into such a new world, without compromising the immense amount of experience that has gone into traditional methods over the last decades.

Research is already being conducted around dynamic bundling, continuous pricing, ancillary pricing, classless revenue management and dynamic personalisation of the offer, as well as into how the various parts of an offer can be best presented to a buyer. In addition, many discussions are taking place about the best ways to implement the new technology, what transition steps may be required and how this effects revenue management organisations and work processes.

For this special edition of the Journal a number of papers have been contributed that cover many of the above aspects starting with a general overview, followed by examples of practical implementation experiences and challenges and finally some results from research work already done in offer optimisation. 
The first paper is written by Sebastien Touraine, Head of Dynamic Offer at IATA. Sebastien is facilitating the Dynamic Offer Working Group, which consists of industry representatives including airlines, revenue management and pricing system vendors, GDSs, OTAs and traditional travel agents. The objective of this group is to structure the discussion and define common terminologies that will help the different players to "talk the same language". The article summarises the trends around dynamic offers across the airline industry and provides a framework to rate the maturity levels of product and price determination. It is therefore an ideal introduction into the topic.

Jost Daft (Lufthansa) together with Sascha Albers and Sebastian Stabenow (University of Antwerp) have put together a framework and implementation guideline, which is intended to support airlines during the transformation to a customer-centric retailing process.

Octavian Oancea (Wizz Air) has conducted a customer survey to gain insights into consumer behavioural economics regarding the impact on the offer design. In his article he covers the effect of the graphical presentation on the decision to buy. In addition, he covers the influence on the consumer when additional product features are included in the bundle or are separately available for a fee.

The introduction section is followed by two papers covering solutions which have been tested or implemented in production.

Mourad Boudia, Suraj Mohamed, Nicolas Bondoux and Thierry Delahaye (Amadeus) give a description of a process that was applied to a real case study at a midsize carrier. The concept behind this approach is to combine the more traditional segmentation of customers using historical booking data with survey data. Like Octavian the survey covers customer preference of products and features. The two aspects are combined to create offers and price them using estimated willingness-to-pay. A simulation was then used to determine the best performing offers.

Madhusudan Rao Kummara, Bhaskara Rao Guntreddy, Ines Garcia Vega and Yun Hsuan Tai (Etihad) describe a solution implemented at Etihad that applies ML (machine learning) algorithms to establish individual prices for ancillary features. The solution presented here is in full production and determines the prices for bags, seat reservation and cabin upgrades as part of the shopping process.

After an introduction to the topic across the industry, some implementation guidelines and customer feedback, followed by practical implementation examples, this special edition is complemented by two research papers that describe new optimisation methods. The ideas have been tested in PODS (Passenger Origin and Destination Simulator), a tool frequently used to simulate potential revenue impact of optimisation models or heuristics in a competitive airline environment.

The first research paper is looking into heuristics for pricing and optimisation of flight and ancillary service bundles and is jointly written by Kevin K. Wang, a Ph.D. student in Air Transportation Systems at MIT, Michael D. Wittman (Amadeus) and Adam Bockelie (Air Canada).

The second research paper discusses ideas of price optimisation under the assumption that booking class limitations no longer exist and prices can be applied using a continuous curve. Different approaches are explained, and the revenue impact simulated using PODS on multiple competing airlines is presented. The article is the joined work of Bazyli Szymański, a Ph.D. candidate at MIT, Peter P. Belobaba (MIT) and Alexander Papen (Amadeus).

This special edition addresses areas that differ significantly to outline the extensive range of impact the transition to retailing has on the commercial side of airlines. The topics include technical complexity, consumer preferences, implementation challenges, to new ideas about offer optimisation. The diversity of topics provides an idea about the wide scope of offer optimisation, which will open the door to innovations that will fundamentally change revenue management.

COVID-19, the world-wide pandemic that has dramatically impacted the transportation industry has only been covered briefly in the various articles. While COVID-19 is an event that is tremendously damaging the industry, it is still considered to be only temporary. On the other hand, the opportunities provided by offer optimisation and retailing will be long-term and hence will continue beyond the pandemic. Nevertheless, independent of the changes that the crisis will have on future product offers (e.g. travel passes, extra space on the plane, etc.), they will become part of the offer optimisation process.

I hope that reading this edition will spark many new initiatives and research, as there is plenty of room to support and improve this transition. I am strongly convinced that this work will result in a very different, yet more customercentric revenue management and pricing approach.

\section{Reference}

IATA website. New Distribution Capability (NDC) introduction and background information. https://www.iata.org/en/programs/airli ne-distribution/ndc. Accessed 15 Mar 2021.

Publisher's Note Springer Nature remains neutral with regard to jurisdictional claims in published maps and institutional affiliations. 